\title{
From Waste Pickers to Producers: An Inclusive Circular Economy Solution through Development of Cooperatives in Waste Management
}

\author{
Rajesh Buch *D, Alicia Marseille, Matthew Williams, Rimjhim Aggarwal (D) and Aparna Sharma \\ Rob and Melani Walton Sustainability Solutions Service, Arizona State University, Tempe, AZ 85287, USA; \\ Alicia.Marseille@asu.edu (A.M.); Matthew.J.Williams@asu.edu (M.W.); Rimjhim.Aggarwal@asu.edu (R.A.); \\ ashar141@asu.edu (A.S.) \\ * Correspondence: rbuch@asu.edu
}

check for

updates

Citation: Buch, R.; Marseille, A.; Williams, M.; Aggarwal, R.;

Sharma, A. From Waste Pickers to

Producers: An Inclusive Circular

Economy Solution through

Development of Cooperatives in

Waste Management. Sustainability

2021, 13, 8925. https://doi.org/

$10.3390 /$ su13168925

Academic Editor: Alessia Amato

Received: 30 June 2021

Accepted: 9 August 2021

Published: 10 August 2021

Publisher's Note: MDPI stays neutral with regard to jurisdictional claims in published maps and institutional affiliations.

Copyright: (c) 2021 by the authors. Licensee MDPI, Basel, Switzerland. This article is an open access article distributed under the terms and conditions of the Creative Commons Attribution (CC BY) license (https:/ / creativecommons.org/licenses/by/ $4.0 /)$.
Abstract: The world's global plastics waste crisis demands policy coordination and technological solutions to improve waste management systems, and organizations worldwide have created momentum around the concept of a circular economy. This paper advances a holistic, inclusive circular economy framework that aims to empower waste pickers with the following basic pillars: (1) build collaborative networks of stakeholders to enable inclusion of waste pickers; (2) establish cooperative enterprise models to integrate waste pickers into the formal economy; (3) build waste pickers' technical skills and capacity for entrepreneurship; and (4) provide access to technologies and markets that enable waste pickers to manufacture upcycled products.

Keywords: circular economy; inclusiveness; stakeholders; capacity building; entrepreneurship; cooperative business models; collaborative networks

\section{Introduction}

The world faces a global plastics waste crisis that demands policy coordination and technological solutions to improve waste management systems at every stage, including the collection, transport, sorting, treatment, and final disposal or reprocessing of waste. International organizations, governments, and the private sector have created momentum behind rethinking the after-market plastics economy through a circular economy, defined as "keeping materials and products in circulation for as long as possible through practices such as reuse of products, sharing of underused assets, repairing, recycling and remanufacturing ... [and] restoring natural systems, designing out waste, and substituting non-renewable materials with biological and renewable ones" [1]. Circular economy solutions have the potential to drive economic growth [2] and create between 9 and 12 million new jobs worldwide [3] in addition to alleviating the environmental and economic consequences of plastic waste. Critically, circular economy solutions, if designed and implemented with an eye for the needs of vulnerable workers, also offer new opportunities to maximize social equity and economic inclusion.

This paper advances an inclusive circular economy solution that aims to empower waste pickers in the developing world. Waste pickers have the potential to act as environmental stewards by mitigating the effects of waste, contributing to the resilience of urban systems, reducing greenhouse gas (GHG) emissions through recovery of materials from waste streams, and saving energy and preserving natural resources by enabling recycling and reuse [4]. They play critical roles in waste management, but their full potential to contribute to the circular economy remains unrealized due to their marginalized social status, lack of recognition by authorities, and disconnection from the formal economy. Additionally, they face significant occupational hazards and social exclusion, and their livelihoods are at risk of being displaced by private-sector-led waste management approaches. 
Due to the prevalence of plastic waste, combined with its unique harms and relative ease of reprocessing, this paper emphasizes the strong potential of plastics recovery and remanufacturing as an initial input for this approach to catalyzing greater inclusion and entrepreneurial capacity for waste pickers; however, the inclusive circular economy solution described here has wide applicability for nearly any other waste stream. After describing the global plastics crisis, we discuss the unique social, occupational, and economic challenges faced by waste pickers. We then propose a new strategy for empowering waste pickers through education and capacity strengthening that leverages cooperative enterprise models, along with low-cost micro-manufacturing technologies, that will allow waste pickers to create value-added products out of plastic waste-enabling new economic opportunities for waste pickers-as-producers while realizing their enormous potential to accelerate the transition to a circular economy.

\section{The Growth in Plastics Use and Waste}

Plastics are integral to the global economy, acting as an enabling technology in almost every sector of economic activity. For decades, the production of plastics increased at a compound annual growth rate of $8.4 \%$, from $2 \mathrm{Mt}$ in 1950 to $380 \mathrm{Mt}$ in 2015-roughly 2.5 times the compound annual growth rate of global GDP during the same period. Only a relatively small share of plastics produced throughout history have ever been recycled. By one estimate, of the $6300 \mathrm{Mt}$ of plastics produced from 1950-2015, 79\% accumulated in landfills or in the environment, $12 \%$ was incinerated, and only $9 \%$ was recycled [5]. The fate of plastics is invariably intertwined with waste management systems that are poorly optimized for recycling and reuse. Globally $37 \%$ of waste is disposed in landfills, $33 \%$ is openly dumped, $11 \%$ is incinerated for final disposal, and only $19 \%$ is recycled. In low-income countries, $90 \%$ of solid waste is still burned or openly dumped, and low- and middle-income countries are expected to see a threefold increase in total waste production by 2050 [6] — a fact that is especially significant to the solution described here, given the large numbers of informal sector waste pickers in these countries.

\section{Harmful Impact of Plastic Waste}

The harms of plastic waste can broadly be categorized in environmental and economic terms. Regarding the environment, plastic waste contributes to the destruction of natural ecosystems, especially oceans and riverways. Ten rivers account for $88-95 \%$ of plastic debris that makes its way to the ocean [7]. Eight million tons of plastic waste are deposited into oceans each year-the equivalent of dumping a garbage truck full of plastic into the ocean every minute. By 2050, the rate of plastic dumping into the ocean will increase to four dump trucks per minute, and the volume of plastics by weight will exceed that of fish [8]. Plastics that litter the earth also disintegrate into microplastic particles that become atmospheric pollutants. One study recorded 365 microplastic particles per square foot falling from the sky [9]. The health consequences of microplastics inhalation and ingestion are unknown [10]. An additional environmental harm of plastics waste is the production of GHGs from after-use incineration, estimated at $390 \mathrm{Mt}$ in 2012. From now through 2050, GHG emissions from the plastics sector will increase from 1\% of global carbon emissions to $15 \%$, contributing significantly to climate change [8].

The mismanagement of plastic waste also has significant financial impacts. Ninetyfive percent of the material value of plastics packaging, estimated at 80-120 billion USD, is lost after a single usage cycle [8]. Plastics waste annually causes 13 billion USD in damages to marine ecosystems and 1.3 billion USD in losses to tourism, fishing, and shipping industries in the Asia-Pacific Economic Cooperation (APEC) region alone. The total afteruse externalities created by plastic waste, accounting for GHGs emitted in production and incineration, are estimated at 40 billion USD annually [8]. 


\section{Waste Picking as Informal Sector Labor}

The informal sector accounts for $61 \%$ of employment globally-approximately 2 billion people - and comprises $90 \%$ of employment in developing countries [11]. Informal workers are most heavily concentrated in the agricultural sector, but many informal occupations exist ranging from housekeeping to construction. The International Labour Office estimates that in the developing world, $1 \%$ of the urban workforce, or 15 to 20 million people, is engaged in recycling [12]. Known as waste pickers, they collect, wash, sort, and process waste from streets, waterways, and landfills. Waste pickers are generally not compensated for collecting trash, but instead earn income through low-value forms of resource valorization through volatile commodity markets.

International organizations have attempted to determine the number of waste pickers from local to global scales, and although some data are available for cities, country-level and global data are scarce. Waste pickers comprise an estimated $0.1-0.4 \%$ of workers in seven West African cities; $0.7 \%$ of workers in South Africa; and $0.1 \%$ of workers in India [13]. These figures, although proportionately small, represent millions of workers. Some municipal and national governments, such as Brazil, have created employment classifications to monitor the waste picker population and track the economic impacts they create.

The level of organization and labor formality of waste pickers varies, and these two factors bear heavily on their ability to earn a living wage. Generally, waste pickers fall into three categories: unorganized (independent), organized (e.g., through a business collective or union), and contract laborers [13]. Local authorities often maintain informal arrangements with waste pickers who supplement formal private sector contracts by filling small niches in urban waste management. In Pune, India, municipal authorities offer formal recognition to waste pickers, providing identity cards and access to health insurance [14], but this is an exceptional case; in most cities, local authorities reap significant benefits from the contributions of waste pickers without formally recognizing or paying them [15].

\section{Occupational Hazards of Waste Picking}

Informal sector workers are uniquely vulnerable to exploitation and mistreatment and lack the security provided by connection to the formal economy, such as banking services, business licensure, and insurance. Waste pickers are no exception to these dynamics and face unique additional challenges. First, waste picking is an inherently high-risk occupation that brings significant health hazards, such as exposure to hazardous chemicals and biological waste; threats to occupational safety; and lack of access to basic sanitation amenities when working in landfills, such as drinking water, toilets, and places to wash [16]. In one study of waste pickers in Mumbai, India, the "prevalence of morbidities was significantly higher among the waste-pickers, particularly for injuries (75\%), respiratory illness (28\%), eye infection $(29 \%)$, and stomach problems $(32 \%)$, compared to the comparison group $(17 \%, 15 \%, 18 \%$, and $19 \%$ respectively)" [17]. Secondly, waste pickers face social alienation and exclusion, ranging from daily mistreatment and humiliation to police harassment and beatings [18]. Third, waste pickers face a variety of social problems including racial conflict, violence and infighting, theft, insecure living conditions, and substance abuse [16]. Finally, waste pickers are often deprived of opportunities for education and social mobility. In families that rely on waste picking for income, children are often put to work before they can finish school, reinforcing the cycle of social exclusion and poverty [19]. Importantly, women in waste picking may also suffer gender-based income discrimination: One survey showed that where there are larger concentrations of women in informal valorization, junk shops pay women lower rates for materials [14]. 


\section{Economic Vulnerability of Waste Pickers}

Waste pickers' livelihoods are constantly under threat due to their dependence upon volatility-prone commodity markets and the ever-present possibility of losing access to waste streams as municipalities adopt "cleaner" private sector solutions. Both problems are exacerbated by their lack of collective economic and political influence. Consequently, waste pickers are uniquely economically vulnerable and often live at the edge of subsistence: for example, in Mumbai, waste pickers earn between 2.71 and 3.62 USD per day [20].

Labor informality adds to the challenges that waste pickers face as service providers at the bottom of the global waste value chain. The primary value that waste pickers provide is in the highly labor-intensive tasks of door-to-door collection and segregation and preparation of materials for recycling, which are sold to middlemen who pay low pricesgenerally only about $10 \%$ of the acquired value of the materials, or one-third of what they would pay to actors in the formal sector [21]. In recent years, the livelihoods of waste pickers have also become increasingly vulnerable to displacement by the private sector, such as when cities establish contracts with waste management providers-sometimes at the behest of donor agencies [12]. For example, the Inter-American Development Bank and the World Bank have encouraged Latin American countries to adopt Integrated Solid Waste Management (ISWM) solutions that include source reduction, recycling and composting, waste transportation, and landfilling. These systems, if designed without an eye for inclusion of all stakeholders-including the informal sector-may limit waste pickers' access to the waste sources that are most profitable for recycling [19]. Although some municipalities have consulted with waste picker cooperatives in ISWM planning to create complementarities between waste pickers and the private sector, waste pickers are generally left out of deliberation and planning processes that shape their futures [1].

Importantly, top-down, private-sector-implemented approaches to waste management not only put waste pickers at risk financially, but also reinforce the linear economy. Private sector actors handle waste in whatever manner is most profitable, even if it means incineration-which creates 25 times the emissions of recycling [12]. In contrast, waste pickers are incentivized to maximize the quantity and quality of recyclable material for resale, and thus devote significant effort to segregating the waste and connecting to appropriate buyers using their local knowledge. One study of six cities found that where private sector recycling has replaced informal valorization, results have been inconsistent, and recycling plants have tended to show disappointing performance. The study concludes that, partially as a result of waste pickers' reliance on lower technology solutions (such as human and animal transport of waste), "an integration of the informal sector would contribute significantly to reducing GHG emissions, as it results in increases in the quantity of recovered material ... [and] more material recovery at lower environmental cost" [14].

\section{An Inclusive Circular Economy Solution for Waste Pickers}

The transition to a global circular economy is often characterized as a solution to environmental problems, but this effort also presents opportunities to design solutions to alleviate inequity and social exclusion. Prevailing top-down approaches to waste management in developing countries, even if they mobilize waste picker cooperatives to facilitate recycling, encourage a race to the bottom in which waste pickers are squeezed by middlemen and left to the mercy of commodity market price fluctuations. Holistic, inclusive circular economy solutions would allow waste pickers to diversify their operations and develop new revenue streams; increase interdependency between waste pickers and conventional waste management actors to facilitate mutually beneficial cooperation that leverages their distinct competitive advantages; and achieve greater efficiency by shortening waste supply chain movements through decentralized waste processing.

An approach that starts from the bottom up and mobilizes collaborative networks to empower waste pickers with training, organization, and technology will allow them to ascend the value chain by utilizing recyclable materials to manufacture value-added products rather than limiting their role to collecting waste and brokering low-margin sales 
to commodity buyers. The integration of the informal sector into waste management systems can increase recycling rates, while eliminating child labor; provide waste pickers with the benefits of formalization such as healthcare, education, and social recognition; and create new jobs and improved livelihoods [3]. More broadly, an equitable transition to a circular economy will improve occupational health and safety for waste pickers, create opportunities for job and venture creation and skills development, and reduce economic harm and displacement.

Although the needs of waste picker communities vary from city to city and country to country, a holistic, inclusive circular economy solution should incorporate the following basic pillars: (1) foster collaborative networks of international, national, and local stakeholders to support waste pickers; (2) establish and support cooperative enterprise models to integrate waste pickers into the formal economy; (3) build waste pickers' technical skills and capacity for entrepreneurship; and (4) provide access to technologies and markets that enable waste pickers to manufacture upcycled products.

\subsection{Pillar \#1: Building Networks of Stakeholders to Include Waste Pickers}

The waste management ecosystems of developing countries comprise multiple actors, including municipalities, waste pickers and waste picker cooperatives, private waste management companies, purchasers of recyclable material and products, academic institutions, international development organizations, and community-based organizations. Successful ISWM planning can ensure the inclusion of the informal sector by facilitating collaboration between these stakeholders through transparent, accessible, and participatory decision-making and policymaking. Identifying complementary and differentiated roles for waste pickers within ISWM systems can also improve waste diversion rates, such as by capitalizing on their natural incentives to maximize collection and sort waste effectively, and by leveraging their abilities to provide certain services with greater efficiency. Improving the working conditions and income potential of waste pickers-and realizing their full potential to increase recycling rates in order to reduce GHG emissions, improve landfill lifespan and utilization, and maximize the economic value of recyclable materials-requires raising awareness among diverse stakeholders of the benefits that waste pickers provide. Better understanding and measurement of informal valorization activities can contribute to national and international recycling goals [14] and facilitate effective, sustainable collaboration towards common goals related to the empowerment of waste pickers. Raising awareness among diverse stakeholders of the benefits that waste pickers provide, and identifying complementary and differentiated roles for waste pickers within ISWM systems, can ultimately improve waste system operational, financial, and environmental performance, while improving the working conditions and livelihoods of waste pickers.

\subsection{Pillar \#2: Forming and Strengthening Waste Picker Cooperatives}

Waste picker cooperatives have proven to be a successful model for integrating waste pickers into the formal economy and domestic and global supply chains, but realizing their full potential requires targeted efforts to increase inclusion and empowerment, including from international non-governmental organizations and development agencies [3]. Cooperatives are critical to helping waste pickers to secure living wages by increasing their ability to negotiate with municipalities to maintain access to waste and with buyers to secure better prices [11]. They provide job security, improved working conditions and higher wages, resilience to economic shocks, and leadership opportunities for women. Most importantly, they provide connection to the formal economy, as cooperatives are legally recognized entities that are considered to be part of the formal sector [4]. Interventions aimed at empowering waste pickers must therefore invest in the organization of business cooperatives, especially in cases where cooperatives have not yet been formed or are weak [22]. To be effective, solutions should strengthen "the internal organization of 
waste cooperatives by providing better business skills [and] management training, with particular emphasis on the core values and principles particular to cooperatives" [19].

\subsection{Pillar \#3: Capacity Strengthening for Entrepreneurship}

Engaging directly with cooperatives allows local and international stakeholders to work with waste pickers to establish comprehensive, community-based economic development mechanisms. An effective approach for catalyzing enterprise-building should address topics such as financial literacy, venture formation, business skills, technical skills, end market development, and cooperative formation and management. Addressing these issues will empower waste pickers to improve the profitability of their current activities and begin a shift towards diversified livelihoods, such as micro-manufacturing products from recycled materials, that give them a larger stake in national and regional economies. Capacity strengthening will also allow them to maximize their contributions to waste management systems [23].

\subsection{Pillar \#4: Access to Technology for Remanufacturing and Production}

Critically, even waste pickers who are organized into effective cooperatives and trained in new business and entrepreneurship skills still find themselves at the mercy of volatile commodities markets. Recycling machinery is prohibitively expensive for many cooperatives, and even those that sell fully processed bulk recycled material will remain as small players in a vast global market as long as their contributions are limited to the base layer of the recycling value chain [11]. The value added from the work of waste pickers is in collection, sorting, washing, and reselling of waste resources, limiting their ability to secure and reinvest financial resources to expand the scope of their operations to engage in higher value activities.

International organizations can play an important role in helping cooperatives to ascend the value chain by helping them to obtain affordable, low-tech machines that utilize recyclable materials to produce marketable plastic products. They can work with waste picker cooperatives and local authorities to create networks of decentralized micromanufacturing facilities in low-income and underserved neighborhoods, helping to create new revenues that revitalize communities. This approach has the added benefit of shortening waste supply chains, thereby reducing waste transportation costs and emissions, as waste pickers can process and remanufacture waste nearer to the areas in which they collect waste rather than at centralized materials recovery facilities. Several private sector companies in India have demonstrated that the production of upcycled products can be profitable, such as Aarohana Ecosocial Development, which produces crafts and clothing from recycled bags [24]. Examples of the kind of products that can be produced with plastic waste include yoga mats, shoes, clothing, jewelry, athletic gear, backpacks, tools, building materials, and furniture. Machines for micro-manufacturing upcycled products can be obtained at low cost, such as Precious Plastic USA's open-source machinery, which costs less than 10,000 USD for a full set including a shredder, compression oven, extruder, and injector [25].

If waste picker cooperatives can be equipped with the organizational and technological capacity to diversify into the production of value-added products, they can earn higher margins by selling upcycled goods locally, nationally, and even internationally. Local plastic picking and producing cooperatives could scale to become national cooperatives similar to agriculture-based ones, such as the Amul Dairy Cooperative in India, which supports nearly 1 million farmers and generates over 1 billion USD in revenue per year [26]. The revenues provided by waste reprocessing and micro-manufacturing, in turn, will allow cooperatives to be self-sustaining, generating revenues that can support increased member incomes, ongoing venture diversification, and reinvestment into community resources such as education. 


\section{Conclusions: Circular Economy as a Catalyst for Sustainable Development}

Circular economy models are often characterized in terms of concepts such as technological innovation, policy change, industrial systems, and natural capital. These and other conceptual lenses are essential, but an intentional focus on equitable, inclusive economic development that creates new livelihoods and maximizes social value is also necessary to realize the full potential of the circular economy. The case of waste pickers demonstrates how top-down approaches-such as focusing on improving the recyclability of plastics, or companies collaborating to standardize packaging protocols-are insufficient to address the broader spectrum of socioeconomic concerns surrounding the transition to a circular economy, especially the working conditions and livelihoods of workers in developing countries. Although these approaches are necessary, the inclusive circular economy solution for waste pickers articulated here is an example of how a bottom-up approach can also ensure that vulnerable workers are not left behind.

Waste pickers have long been marginalized and treated with suspicion by governments around the world, holding them back from realizing their full potential to contribute to resilient urban ecosystems as key players in effective waste management strategies. Even where waste pickers have organized through business cooperatives, their reliance on traditional business models-based on low-value valorization activities and brokering the sale of recyclables at margins that barely turn a profit-limits their ability to earn a living wage. Cooperatives have proven effective in helping waste pickers to earn better livelihoods, improve their working conditions, and achieve formal recognition from local governments, but these efforts are limited in their ability to create enduring economic stability for waste pickers. For example, in Pune, India, the nearly 3000 members of the Solid Waste Collection and Handling $(\mathrm{SWaCH})$ cooperative provide waste management services to $70 \%$ of the city [27]. However, $\mathrm{SWaCH}$ still faces threats from large scale, privatesector-led approaches that deprive waste pickers of income while driving environmentally unfriendly practices such as waste incineration [28].

A holistic, intentionally designed inclusive circular economy solution can build on the success of cooperatives like SWaCH by mobilizing broad networks of stakeholders from local to international scales to assist waste pickers in forming and maintaining cooperatives and in brokering sustainable arrangements with local authorities that secure their access to waste resources. With the training and technology to manufacture products that can be sold for significantly higher profits than bulk recyclables, these picker-producer cooperatives can diversify their revenues and realize higher returns for their members, catalyzing bottom-up economic growth that has the potential to help waste pickers thrive financially and transform the communities in which they live. Moreover, although plastic waste is an ideal initial focus for this approach, this solution can readily be applied to many other waste streams-including construction debris, textiles, and even organic matter.

Circular economy practices are critical to solving the global waste crisis, but with holistic design that prioritizes inclusion of the world's most vulnerable workers, they can also drive the achievement of sustainable development goals related to poverty, hunger, gender equality, and social inequality [1]. The approach described here is only one example of how the transition to a circular economy can be leveraged to maximize inclusion and equitable outcomes for the world's poorest and ensure that the benefits of the circular economy are accessible to all.

Author Contributions: Conceptualization, R.B., A.M. and M.W.; methodology not applicable; software not applicable; validation, not applicable; formal analysis, not applicable; investigation, not applicable; resources, not applicable; data curation, not applicable; writing-original draft preparation, M.W., A.S.; writing-review and editing, R.B., A.M., M.W. and R.A.; visualization, not applicable; supervision, R.B., A.M. and R.A.; project administration, not applicable; funding acquisition, not applicable. All authors have read and agreed to the published version of the manuscript.

Funding: This research received no external funding.

Institutional Review Board Statement: Not applicable. 
Informed Consent Statement: Not applicable.

Data Availability Statement: Data sharing not applicable.

Conflicts of Interest: The authors declare no conflict of interest.

\section{References}

1. Schroeder, P. Promoting a Just Transition to an Inclusive Circular Economy. Royal Institute of International Affairs. 2020. Available online: https:/ / circulareconomy.europa.eu/platform/sites/default/files/2020-04-01-inclusive-circular-economy-schroder.pdf (accessed on 25 April 2020).

2. McCarthy, A.; Dellink, R.; Bibas, R. The Macroeconomics of the Circular Economy Transition: A Critical Review of Modelling Approaches. OECD Environ. Work. Pap. 2018, 130. [CrossRef]

3. Wilson, D.C.; Rodic, L.; Modak, P.; Soos, R.; Carpintero, A.; Velis, K.; Iyer, M.; Simonett, O. Global Waste Management Outlook. 2015. Available online: http://web.unep.org/ourplanet/september-2015/unep-publications/global-waste-management-outlook (accessed on 20 April 2020).

4. Gutberlet, J. Waste Picker Social Economy Organizations Addressing the Sustainable Development Goals. In Implementing the Sustainable Development Goals: What Role for Social and Solidarity Economy? UNTFSSE Knowledge Hub (Online): Geneva, Switzerland, 2019; Available online: https://knowledgehub.unsse.org/wp-content/uploads/2019/06/199_Gutberlet_Wastepicker-social-economy_En.pdf (accessed on 12 April 2020).

5. Geyer, R.; Jambeck, J.R.; Law, K.L. Production, Use, and Fate of All Plastics Ever Made. Sci. Adv. 2017, 3, e1700782. [CrossRef] [PubMed]

6. Kaza, S.; Yao, L.; Bhada-Tata, P.; Woerden, F.V. What a Waste 2.0: A Global Snapshot of Solid Waste Management to 2050; World Bank Publications: Washington, DC, USA, 2018.

7. Schmidt, C.; Krauth, T.; Wagner, S. Export of Plastic Debris by Rivers into the Sea. Environ. Sci. Technol. 2017, 51, 12246-12253. [CrossRef] [PubMed]

8. Ellen Macarthur Foundation. The New Plastics Economy: Rethinking the Future of Plastics \& Catalysing Action. Ellen Macarthur Foundation. 2017. Available online: https://www.ellenmacarthurfoundation.org/assets/downloads/publications/NPECHybrid_English_22-11-17_Digital.pdf (accessed on 1 April 2020).

9. Allen, S.; Allen, D.; Phoenix, V.R.; Le Roux, G.; Durántez Jiménez, P.; Simonneau, A.; Binet, S.; Galop, D. Atmospheric Transport and Deposition of Microplastics in a Remote Mountain Catchment. Nat. Geosci. 2019, 12, 339-344. [CrossRef]

10. Leahy, S. "Microplastics Are Raining Down from the Sky." National Geographic. 15 April 2019. Available online: https: / / www.nationalgeographic.com/environment/2019/04/microplastics-pollution-falls-from-air-even-mountains (accessed on 21 April 2020).

11. WIEGO. Counting the World's Informal Workers: A Global Snapshot. 2019. Available online: https://www.wiego.org/sites/ default/files/resources/files/WIEGO-Global-Statistics-Snapshot-Pamphlet-English-2019.pdf (accessed on 12 April 2020).

12. WIEGO. Urban Informal Workers and the Green Economy. Available online: https://www.wiego.org/sites/default/files/ resources/files/WIEGO_Urban_Informal_Workers_Green_Economy.pdf (accessed on 12 April 2020).

13. Awad, A.B.; de Medina, R.; Vanek, J. Women and Men in the Informal Economy: A Statistical Picture, 2nd ed.; International Labour Office: Geneva, Switzerland, 2013.

14. Gunsilius, E.; Chaturvedi, B.; Scheinberg, A. The Economics of Informal Sector in Solid Waste Management. CWG/GIZ. 2011. Available online: https:/ / www.giz.de/en/downloads/giz2011-cwg-booklet-economicaspects.pdf (accessed on 15 April 2020).

15. Dias, S.M. Waste Pickers and Cities. Environ. Urban. 2016, 28, 375-390. [CrossRef]

16. Schenck, C.J.; Blaauw, P.F.; Viljoen, J.M.; Swart, E.C. Exploring the Potential Health Risks Faced by Waste Pickers on Landfills in South Africa: A Socio-Ecological Perspective. Int. J. Environ. Res. Public Health 2019, 16, 2059. [CrossRef] [PubMed]

17. Chokhandre, P.; Singh, S.; Kashyap, G.C. Prevalence, Predictors and Economic Burden of Morbidities among Waste-Pickers of Mumbai, India: A Cross-Sectional Study. J. Occup. Med. Toxicol. 2017, 12, 30. [CrossRef] [PubMed]

18. Dandapani, S. Unpaid and Undervalued, How India's Waste Pickers Fight Apathy to Keep Our Cities Clean, the News Minute [Online]. 30 November 2017. Available online: https:/ / www.thenewsminute.com/article/oppressed-and-unrecognised-lifewaste-pickers-crucial-india-s-sanitation- (accessed on 15 April 2020).

19. Marello, M. Waste Pickers: Strategies to Enhance Livelihoods. Master's Thesis, Boston University, Boston, MA, USA, 2013. Available online: http:/ / www.bu.edu/pardeeschool/files/2014/08/Sample-Policy-Paper-1.pdf (accessed on 20 April 2020).

20. Global Alliance of Waste Pickers. City Report: Interview with a Local Waste Picker. Available online: https://globalrec.org/city/ mumbai/ (accessed on 15 April 2020).

21. WIEGO. Waste Pickers. Available online: https://www.wiego.org/informal-economy/occupational-groups/waste-pickers\#stats (accessed on 12 April 2020).

22. Dias, S. Three Ways Waste Pickers Can Be Included in the New Circular Economy. Equal Times [Online]. 28 March 2018. Available online: https:/ / www.equaltimes.org/three-ways-waste-pickers-can-be?lang=en (accessed on 15 April 2020).

23. Talbot, T.C. A Green Army Is Ready to Keep Plastic Waste Out of the Ocean. Scientific American [Online]. 7 October 2019. Available online: https:/ / blogs.scientificamerican.com/observations/a-green-army-is-ready-to-keep-plastic-waste-out-of-theocean/ (accessed on 24 April 2020). 
24. Aarohana Ecosocial Development. Watch Our Story! Available online: https:/ / aarohana.org/how-its-made/ (accessed on 1 May 2020).

25. Precious Plastic USA. Machines. Available online: https://www.preciousplastic-usa.com/machines (accessed on 24 April 2020).

26. Amul Dairy. An Overview. Available online: http://www.amuldairy.com (accessed on 20 April 2020).

27. SWaCH homepage. Available online: https://swachcoop.com (accessed on 24 April 2020).

28. Talbot, T.C. Picking Dignity. Resource Recycling [Online], Updated 6 February 2018. 4 September 2017. Available online: https:/ / resource-recycling.com/recycling/2017/09/04/picking-dignity/ (accessed on 24 April 2020). 